Kazuma Nakagawa, MD

Megan A. Vento, BS

Marissa M. Ing, MSW

Todd B. Seto, MD, MPH

Correspondence to

Dr. Nakagawa:

kazuma.nakagawa@hawaii.edu

\section{Racial disparities in} methamphetamine-associated intracerebral hemorrhage

\section{ABSTRACT}

Objective: To assess racial disparities in the prevalence of methamphetamine-associated intracerebral hemorrhage (Meth-ICH) among Native Hawaiians and other Pacific Islanders (NHOPI).

Methods: Prospectively collected data from an ongoing, multiethnic, single-center cohort study were analyzed. The inclusion criteria for the cohort study required that patients be adult lage 18 years or older) residents of Hawaii with nontraumatic spontaneous intracerebral hemorrhage (ICH). Patients of race other than white, Asian, or NHOPI were excluded. Determination of Meth$\mathrm{ICH}$ was made prospectively by positive urine toxicology result and lack of other clinically suspected ICH etiology. Prevalence of Meth- $\mathrm{ICH}$ among NHOPI was compared with that of white and Asian patients.

Results: A total of 193 patients (white 16\%, Asian 61\%, NHOPI 23\%) were analyzed. NHOPI were younger than white (54 \pm 15 vs $68 \pm 15$ years, respectively, $p=0.0001$ ) and Asian (vs $65 \pm 16$ years, $p=0.0001$ ) patients. Overall, 25 (13\%) Meth-ICHs (mean age: $49 \pm 6$ years, range: 33-56 years) were identified. NHOPI had higher prevalence of Meth-ICH compared with white ( $24 \%$ vs $0 \%$, respectively, $p=0.003$ ) and Asian (vs $12 \%, p=0.046$ ) patients. The observed age differences between the racial groups persisted even after excluding the MethICH group ( $p<0.01$ for all comparison).

Conclusions: NHOPI have higher prevalence of Meth-ICH compared with white and Asian patients. However, the age disparity is not entirely driven by methamphetamine abuse. Neurology ${ }^{\circledR}$ 2015;84:995-1001

\section{GLOSSARY}

ICH = intracerebral hemorrhage; $\mathbf{M A C}=$ methamphetamine-associated cardiomyopathy; Meth-ICH = methamphetamineassociated intracerebral hemorrhage; NHOPI = Native Hawaiians and other Pacific Islanders; QMC $=$ Queen's Medical Center.

Intracerebral hemorrhage $(\mathrm{ICH})$ is a severe form of hemorrhagic stroke $(10 \%-15 \%$ of all strokes) that results in disproportionately high morbidity and mortality. ${ }^{1}$ Minority groups, blacks and Hispanics, are the most frequently studied populations, and have been shown to have a higher incidence of $\mathrm{ICH}$ and younger age of disease onset than whites. ${ }^{2-4}$ A more recent retrospective study that assessed Native Hawaiians and other Pacific Islanders (NHOPI), a racial minority group that has historically been aggregated with Asians in prior studies, also found similar disparities. ${ }^{5}$ In that study, NHOPI with ICH were more than a decade younger than white and Asian groups, but the impact of methamphetamine, a sympathomimetic recreational drug that has been associated with ICH, was not addressed. Historically, NHOPI have a higher prevalence of methamphetamine abuse compared with other major racial-ethnic groups in Hawaii. ${ }^{6-8}$ Therefore, it is unclear whether younger age of ICH observed in NHOPI is mostly related to the high prevalence of young methamphetamine abusers, or attributable to early onset of cardiovascular risk factors.

Therefore, we prospectively determined the prevalence of methamphetamine-associated ICH (Meth-ICH) among a population that consists of large number of NHOPI. The primary

From The Queen's Medical Center (K.N., M.A.V., M.M.I., T.B.S.), Honolulu, HI; and Department of Medicine (K.N., T.B.S.), John A. Burns School of Medicine, University of Hawaii, Honolulu.

Go to Neurology.org for full disclosures. Funding information and disclosures deemed relevant by the authors, if any, are provided at the end of the article. 
hypothesis was that NHOPI with ICH would have significantly higher prevalence of MethICH than white or Asian population. The secondary aim was to show racial disparities after excluding the Meth-ICH group with the hypothesis that not all of the observed age differences are explained by the methamphetamine abuse in the young population.

METHODS A multiethnic prospective cohort study of patients with ICH has been conducted since July 2011 at The Queen's Medical Center (QMC) to assess racial disparities in long-term functional outcome after $\mathrm{ICH}$. The clinical data that were prospectively collected for this ongoing observational cohort study were analyzed to compare the prevalence of Meth-ICH among white, Asian, and NHOPI groups. QMC is a 505-bed medical center located on Oahu, the largest hospital in Hawaii and the tertiary referral center for the Pacific Basin (Hawaii, American Samoa, the Commonwealth of the Northern Mariana Islands, Micronesia, and the US territories of Guam). QMC has the only Joint Commission-certified Primary Stroke Center and the only Neuroscience Intensive Care Unit in the state of Hawaii. Since ICH is a condition that is preferably treated in the Neuroscience Intensive Care Unit, ${ }^{9}$ QMC is the primary referral center for acute management of patients with $\mathrm{ICH}$ from other major islands.

Patients. All patients with ICH hospitalized at QMC were prospectively screened for enrollment by the investigators and research staff. Inclusion criteria for the multiethnic prospective cohort study included the following: age 18 years or older; nontraumatic $\mathrm{ICH}$ with confirmation by CT; and resident of Hawaii for more than 3 months in a household with a telephone. Exclusion criteria were ICH related to ruptured cerebral aneurysm, ICH related to brain tumor, or hemorrhagic conversion of ischemic stroke.

Study procedures. This was an observational study and no intervention was provided. Patient demographic information (race, marital status, income level, insurance status, etc.) was obtained directly from the patients or their family if the patients were incapacitated. Since mixed racial background is relatively common in Hawaii, race was defined as the single racial/cultural background that the patient most closely associated with and was based on patient self-identification or family's identification if the patient was incapacitated. Race was ultimately categorized as white, Asian, NHOPI, or other. According to the definition used in the 2010 Census, NHOPI was defined as persons with origins in any of the original peoples of Hawaii, Guam, Samoa, or other Pacific Islands. ${ }^{10}$ Clinical and radiographic information was abstracted from the electronic medical records and was confirmed by the patients, their family, or the treating team if needed. Initial Glasgow Coma Scale score was obtained from the medical record. Regular visit to a primary care physician was defined as a minimum of one routine visit per year over the past year. All initial head CT scans were reviewed by one of the physician investigators (K.N.) using a standardized protocol. Hematoma volume was measured using the previously described $\mathrm{ABC} / 2$ method. ${ }^{11}$ Presence of intraventricular hemorrhage was recorded, and $\mathrm{ICH}$ location was coded as deep (basal ganglia or thalamus), lobar, brainstem, cerebellum, or primary intraventricular hemorrhage.

Outcome measures. The prevalence of Meth-ICH was the clinical outcome measure for this study. Determination of Meth-ICH was made prospectively by positive urine toxicology result and lack of other clinically suspected etiology for $\mathrm{ICH}$. Obtaining urine toxicology on admission for patients with $\mathrm{ICH}$ is a routine practice at our institution. However, the final decision to obtain this test was at the discretion of the treating physicians. Therefore, some patients with very low clinical suspicion for Meth-ICH or patients with other known causes of ICH did not have urine toxicology performed.

Standard protocol approvals, registrations, and patient consents. This study was approved by the University of Hawaii institutional review board, and written informed consent was obtained from the patient or legally authorized surrogate decision-maker.

Statistical analysis. Data were analyzed using commercially available statistical software (SPSS 22.0; SPSS, Inc., Chicago, IL). We excluded patients identified as "other" race. Patient characteristics were summarized using descriptive statistics appropriate to variable type. NHOPI were compared with white and Asian groups using the $\chi^{2}$ test for categorical data, 2-tailed $t$ test for normally distributed, continuous variables, and MannWhitney $U$ test for nonparametric data (Glasgow Coma Scale). The prevalence of Meth-ICH among NHOPI was compared with that of white and Asian patients. For our secondary aim, NHOPI characteristics were compared with characteristics of white and Asian groups after excluding patients with MethICH. The required sample size of 193 patients with ICH was approximated to include a minimum of $43 \mathrm{NHOPI}$ and 38 white patients to detect at least 10 -year age difference ( $\mathrm{SD}=16$ years) between the 2 racial groups with $80 \%$ power. Levels of $p<0.05$ were considered statistically significant.

RESULTS A total of 367 patients were screened for enrollment between July 2011 and January 2014. Of the 367 patients, the following patients were excluded: 28 patients with trauma-related ICH, 16 patients because of non-Hawaii residence, 15 patients with tumor-related ICH, 8 patients with aneurysm-related $\mathrm{ICH}, 4$ patients because of ischemic stroke with hemorrhagic conversion, and one patient for age younger than 18 years. Among the remaining 295 patients, 95 patients were excluded because of no family available for consent (26), language barrier (21), expired before recruitment (12), patient/family declined (11), discharged before recruitment (9), homeless and lack telephone (6), radiographic lesion that appeared as ICH initially but was determined to be other diagnosis (5), postoperative hemorrhage (3), and prisoner (2). Seven patients of "other" race were excluded from the study: Portuguese (3), black (2), Hispanic (1), and Puerto Rican (1).

Table 1 provides the demographic and clinical information of 193 patients (white 16\%, Asian $61 \%$, NHOPI 23\%) who were included in the study. Overall, NHOPI patients had younger age, lower socioeconomic status, lower rate of regular visit to their primary care physician, and higher rate of hypertension and diabetes compared with white patients. In this cohort, a total of 119 (62\%) urine toxicology tests were performed. NHOPI received more frequent urine toxicology tests compared with white 
Table 1 Clinical characteristics of the patients with $\mathrm{ICH}$ by race

\begin{tabular}{|c|c|c|c|}
\hline & NHOPI & White & Asian \\
\hline No. of patients & 45 & 30 & 118 \\
\hline Age, y & $54 \pm 15$ & $68 \pm 15^{a}$ & $65 \pm 16^{a}$ \\
\hline Female & $14(31)$ & $10(33)$ & $54(46)$ \\
\hline Married & $24(53)$ & $17(57)$ & $65(55)$ \\
\hline No health insurance & $8(18)$ & 1 (3) & $12(10)$ \\
\hline Annual household income $<\$ 15,000$ & $18(40)$ & $5(17)^{a}$ & $20(17)^{a}$ \\
\hline Regular visit to a primary care physician & $17(42)$ & $21(72)^{\mathrm{a}}$ & $73(67)^{a}$ \\
\hline Hypertension & $37(82)$ & $18(60)^{\mathrm{a}}$ & $95(81)$ \\
\hline Diabetes mellitus & $19(42)$ & $5(17)^{a}$ & $27(23)^{a}$ \\
\hline Hypercholesterolemia & $19(42)$ & $15(50)$ & $55(47)$ \\
\hline Coronary artery disease & 4 (9) & $6(20)$ & $12(10)$ \\
\hline Atrial fibrillation & $7(16)$ & $8(27)$ & $19(16)$ \\
\hline Coagulopathy (INR $\geq 1.5$ ) & $10(22)$ & $6(20)$ & $16(14)$ \\
\hline Methamphetamine-associated ICH & $11(24)$ & $0(0)^{a}$ & $14(12)^{a}$ \\
\hline Initial SBP, mm Hg & $186 \pm 38$ & $171 \pm 32$ & $175 \pm 34$ \\
\hline Initial DBP, mm Hg & $105 \pm 24$ & $95 \pm 22$ & $98 \pm 26$ \\
\hline Initial GCS score & $12(4,15)$ & $14(6,15)$ & $12(6,15)$ \\
\hline \multicolumn{4}{|l|}{ Hematoma location } \\
\hline Deep (basal ganglia or thalamus) & $22(49)$ & $14(47)$ & $65(55)$ \\
\hline Lobar & $12(27)$ & $13(43)$ & $36(31)$ \\
\hline Cerebellum & $6(13)$ & $3(10)$ & $11(9)$ \\
\hline Brainstem & 4 (9) & $0(0)$ & $1(1)$ \\
\hline Primary intraventricular hemorrhage & 1 (2) & $0(0)$ & $5(4)$ \\
\hline Intraventricular hemorrhage & $22(49)$ & $12(41)$ & $58(50)$ \\
\hline Hematoma volume, $\mathrm{cm}^{3}$ & $28 \pm 32$ & $42 \pm 45$ & $39 \pm 46$ \\
\hline Hospital length of stay, d & $15 \pm 19$ & $8 \pm 8$ & $10 \pm 11^{a}$ \\
\hline Do Not Resuscitate order, any & $10(33)$ & $11(24)$ & 41 (35) \\
\hline Hospital mortality & $8(18)$ & $8(27)$ & $32(27)$ \\
\hline
\end{tabular}

Abbreviations: DBP = diastolic blood pressure; GCS = Glasgow Coma Scale; ICH = intracerebral hemorrhage; INR = international normalized ratio; IQR = interquartile range; NHOPI = Native Hawaiians and other Pacific Islanders; $\mathrm{SBP}=$ systolic blood pressure.

${ }^{a} p<0.05$.

Data are $\mathrm{n}(\%)$, mean $\pm \mathrm{SD}$, or median (interquartile range). NHOPI (reference group) were compared with white and Asian groups.

(80\% vs $50 \%$ respectively, $p=0.01$ ) and Asian (vs $58 \%$ respectively, $p=0.01$ ) patients. Overall, a total of 25 (13\%) patients with Meth-ICH (mean age: $49 \pm$ 6 years; range: $33-56$ years) were identified. NHOPI patients had a higher prevalence of Meth-ICH compared with white $(24 \%$ vs $0 \%$ respectively, $p=0.003)$ and Asian (vs $12 \%, p=0.046$ ) patients.

The observed racial disparities after accounting for Meth-ICH persisted. After excluding the Meth-ICH group, NHOPI patients were still younger than white (NHOPI: $54 \pm 17$ years vs white: $68 \pm 15$ years, respectively, $p=0.001$ ) and Asian (vs Asian: $67 \pm$ 16 years, $p=0.0001$ ) patients. Compared with the white and Asian groups, the NHOPI group had a higher prevalence of diabetes (NHOPI: $41 \%$ vs white: $17 \%, p=0.03$; vs Asian: $24 \%, p=0.05$ ) and lower rate of regular visits to their primary care physicians (NHOPI: $37 \%$ vs white $72 \%, p=0.006$; vs Asian 75\%, $p<0.0001)$.

Clinical and radiographic comparisons of the Meth-ICH group $(\mathrm{n}=25)$ and non-Meth-ICH group $(\mathrm{n}=168)$ are shown in table 2 . The Meth$\mathrm{ICH}$ group had younger age, lower socioeconomic status, lower rate of regular visits to their primary care physicians, higher rate of no insurance, and presented with higher systolic and diastolic blood pressure compared with the non-Meth-ICH group. Overall, 96\% of the Meth-ICHs occurred in a location that is 
Table 2 Comparison of Meth-ICH and non-Meth-ICH

\begin{tabular}{|c|c|c|c|}
\hline & Meth-ICH & Non-Meth-ICH & p Value \\
\hline No. of patients & 25 & 168 & \\
\hline Age, y & $49 \pm 6$ & $65 \pm 17$ & $<0.0001$ \\
\hline Female & $6(24)$ & $72(43)$ & 0.07 \\
\hline Race & & & 0.007 \\
\hline White & $0(0)$ & $30(18)$ & \\
\hline Asian & $14(56)$ & $104(62)$ & \\
\hline NHOPI & $11(44)$ & $34(20)$ & \\
\hline No health insurance & $7(28)$ & $14(8)$ & 0.003 \\
\hline Annual household income $<\$ 15,000$ & $13(52)$ & $30(18)$ & 0.0001 \\
\hline Regular visit to a primary care physician & $6(25)$ & $105(68)$ & $<0.0001$ \\
\hline Known history of hypertension & $20(80)$ & $130(77)$ & 0.77 \\
\hline Initial SBP, mm Hg & $197 \pm 33$ & $174 \pm 34$ & 0.002 \\
\hline Initial DBP, mm Hg & $115 \pm 20$ & $97 \pm 25$ & 0.001 \\
\hline Initial GCS score & $11(5,15)$ & $12(7,15)$ & 0.89 \\
\hline Hematoma location & & & $<0.0001$ \\
\hline Deep (basal ganglia or thalamus) & $15(60)$ & $86(51)$ & \\
\hline Lobar & $1(4)$ & $60(36)$ & \\
\hline Cerebellum & $5(20)$ & $15(9)$ & \\
\hline Brainstem & $4(16)$ & $1(1)$ & \\
\hline Primary intraventricular hemorrhage & $0(0)$ & 6 (3) & \\
\hline Intraventricular hemorrhage & $11(44)$ & $81(49)$ & 0.66 \\
\hline Hematoma volume, $\mathrm{cm}^{3}$ & $23 \pm 27$ & $39 \pm 45$ & 0.10 \\
\hline Hospital length of stay, d & $9 \pm 11$ & $11 \pm 13$ & 0.54 \\
\hline Hospital mortality & $6(24)$ & $42(25)$ & 0.91 \\
\hline
\end{tabular}

Abbreviations: DBP = diastolic blood pressure; GCS = Glasgow Coma Scale; ICH = intracerebral hemorrhage; Meth-ICH = methamphetamine-associated intracerebral hemorrhage; NHOPI = Native Hawaiians and other Pacific Islanders; SBP = systolic blood pressure.

Data are $\mathrm{n}(\%)$, mean $\pm \mathrm{SD}$, or median (interquartile range). Meth-ICH group was compared with non-Meth-ICH group.

considered typical for hypertensive ICH (basal ganglia, thalamus, cerebellum, or brainstem).

DISCUSSION This study showed that NHOPI have higher prevalence of Meth-ICH compared with whites and Asians, and further adds to the growing recognition of methamphetamine-related health issues in the NHOPI community. ${ }^{6-8,12}$ Historically, methamphetamine abuse was most frequently reported in Hawaii and on the West Coast, but now has spread eastward to involve much of the United States. ${ }^{13}$ Overall, there is an alarming increase in the general trend of substance abuse and the incidence of young strokes in the United States, ${ }^{14}$ and highlights the importance of testing for illicit drugs and providing appropriate counseling to young patients with drugrelated strokes.

Methamphetamine is a potent sympathomimetic that increases the release of dopamine, norepinephrine, epinephrine, and serotonin, ${ }^{15}$ which result in acute hypertension and tachycardia, ${ }^{16}$ and chronic hypertension with chronic use. ${ }^{17}$ Methamphetamine abuse is a well-known cause of spontaneous ICH, ${ }^{18-27}$ although the exact mechanism is unclear. Some postmortem studies have suggested acute necrotizing angiitis, leading to fibrinoid necrosis, thinning of the tunica media and intima, and microaneurysm formation. ${ }^{19,27-32}$ However, other studies have shown no evidence of inflammation or vasculitis, ${ }^{33-35}$ suggesting that much of Meth-ICH may be attributable to cumulative burden of methamphetamine-induced high blood pressure. In fact, $96 \%$ of Meth-ICHs in our study had hematoma in a location that is consistent with hypertensive ICH, suggesting that this may be an accelerated hypertensive pathology.

In addition to cerebrovascular toxicity, methamphetamine can cause cardiac toxicity, including cardiomyopathy, arrhythmia, coronary vasospasm, sudden 
cardiac death, and dissection of aorta, coronary, and carotid arteries. ${ }^{13,36}$ Among these conditions, methamphetamine-associated cardiomyopathy (MAC) is, perhaps, the most extensively reported cardiac pathology. Similar to Meth-ICH, the widely accepted mechanism of MAC is chronic catecholamine toxicity leading to myocardial necrosis and fibrosis, and eventually dilated cardiomyopathy. ${ }^{36}$ Like our study, high prevalence of MAC has been reported in NHOPI among a heart failure cohort in Hawaii. ${ }^{12}$

In this study, even after excluding the Meth-ICH group, we were able to show that NHOPI with ICH are still significantly younger compared with white and Asian patients, which suggests that the $\mathrm{ICH}$

\section{Comment: Association or causation measures in racial disparities}

Racial and ethnic disparities are well established in every subtype of stroke. An understudied group is Native Hawaiian/Pacific Islanders (NHOPI); the accompanying article by Nakagawa et al. ${ }^{1}$ expands our knowledge about disparities involving NHOPI. Their results indicate a higher proportion of intracerebral hemorrhage $(\mathrm{ICH})$ and methamphetamine-related $\mathrm{ICH}$ among NHOPI as compared to whites and Asians. While the numbers seem compelling, it is worth reviewing the methods and measures of association.

The study uses descriptive rather than analytic methodology. The statistical measures indicate differences in the proportion of patients with specific factors such as hypertension, diabetes, or methamphetamine exposure; while these differences suggest the presence of disparities, the lack of analytic methodology limits the conclusions substantially. To determine the greater attributable risk of methamphetamine among NHOPI vs other race/ethnic groups, a cohort followed for a period of time, during which the incidence of $\mathrm{ICH}$ is measured and compared by groups according to the presence or absence of any exposure of interest, in this case methamphetamine use, would be ideal. Alternatively, using a case-control methodology with cases obtained in a population-based methodology and controls matched by demographic criteria may be compared according to their exposure to methamphetamine. With either of these approaches the risk ratio or odds ratio can be estimated, strengthening the certainty of the conclusions about causal association..$^{2}$ However, at an incidence rate of 20 per 100,000 per year, a cohort of 100,000 individuals followed over 5 years would be required, making a prospective cohort study cost-prohibitive. A case-control study may require resources to obtain population-based controls and a population-wide case collection, and preliminary data such as the race/ethnic disparities reported here may support such an effort in the future.

Furthermore, it would also be ideal if the entire population were screened for the risk factor of interest. The current study included 45 total NHOPI and 30 white patients and the screening for methamphetamine use was performed in 34 $(80 \%)$ NHOPI but only $15(50 \%)$ white patients, indicating the possibility of identification/selection bias. This, in turn, affects any sample size calculation based on risk differences between groups, also limiting the conclusions. Notwithstanding these limitations, the study signals the need for further research with alternative methods to understand the determinants of $\mathrm{ICH}$ and the burden of typical vascular risk factors and of methamphetamine abuse in the NHOPI population.

1. Nakagawa K, Vento MA, Ing MM, Seto TB. Racial disparities in methamphetamineassociated intracerebral hemorrhage. Neurology 2015;84:995-1001.

2. Kelsey JL, Whittemore AS, Evans AS, Thompson W. Methods in Observational Epidemiology, 2nd edition. New York: Oxford University Press; 1996.

Salvador Cruz-Flores, MD, MPH, FAAN Daniel Woo, MD, MS

From the Department of Neurology (S.C.-F.), Texas Tech University Health Sciences Center at El Paso; and the University of Cincinnati College of Medicine (D.W.), OH.

Study funding: No targeted funding reported.

Disclosure: S. Cruz-Flores receives honoraria for serving as member of adjudication committees in clinical trials for Lilly and Novo Nordisk. D. Woo receives funding from the NIH (NS36695, NS69208, NS69763). Go to Neurology.org for full disclosures. disparities are not entirely explained by the high prevalence of young methamphetamine abusers among NHOPI. Much of the observed disparities are likely attributable to early onset and higher burden of uncontrolled cardiovascular risk factors, as suggested by the lower rate of regular visits to primary care physicians by NHOPI compared with white or Asian patients.

The strength of this study is that this is the largest cohort of patients with Meth-ICH reported. Previous to our study, a retrospective study of 11 patients with Meth-ICH was the largest case series. ${ }^{22}$ Furthermore, the diagnosis of Meth-ICH was determined prospectively in our study, which strengthens the accuracy of the diagnosis. The sample size was calculated to have enough power to detect an age difference of 10 years between NHOPI and white groups. The study site recruited a relatively large NHOPI population, which has been historically underrepresented in prior stroke studies. The limitation of this study is that this is a single-center study, which makes our results potentially not generalizable to other populations. Since the study site is located near downtown Honolulu, there may have been a geographic and selection bias toward lower socioeconomic NHOPI methamphetamine abusers who may be more likely to present to our medical center compared with other hospitals in Hawaii. However, since $81 \%$ of our cohorts were Honolulu County residents and our medical center is the primary referral center for most $\mathrm{ICH}$ interhospital transfers, we believe that our study population is reasonably representative of the Honolulu County. Another limitation of the study is that 21 patients were excluded because of language barrier. Since these patients are likely minorities, presumably a high proportion of other Pacific Islander population (i.e., Micronesians), exclusion of these non-English populations may have masked the impact of NHOPI race on $\mathrm{ICH}$ disparities. Also, it is possible that white patients with Meth-ICH were excluded from the cohort study because of lack of family consent since they may have higher likelihood of family not living in Hawaii compared with NHOPI. Furthermore, there were no ICH-free controls in this study, which weakens the argument that methamphetamine abuse was the direct cause of ICH. Lastly, we cannot exclude the possibility of selection bias toward NHOPI with Meth-ICH since urine toxicology was performed more frequently in NHOPI compared with white and Asian patients. However, many of the white and Asian patients who did not receive urine toxicology had other plausible causes of ICH, such as arteriovenous malformation or anticoagulantrelated coagulopathy, making it less likely that the differences in the rate of urine toxicology performed affected our observation. 
This study showed that Meth-ICH is not a rare cause of $\mathrm{ICH}$, and is more frequently seen among young patients. NHOPI patients had a higher prevalence of Meth-ICH compared with white and Asian patients. However, even after excluding the MethICH group, NHOPI still had younger age, higher prevalence of diabetes, and lower rate of regular primary care visits, suggesting that observed health disparities are not entirely driven by the methamphetamine abuse in the community.

\section{AUTHOR CONTRIBUTIONS}

K.N. participated in the conception and design of the study, the acquisition of data, the analysis and interpretation of data, and was responsible for drafting and finalizing the manuscript. M.A.V. participated in the acquisition of data and helped to draft and finalize the manuscript. M.M.I. participated in the acquisition of data and helped to draft and finalize the manuscript. T.B.S. participated in the study supervision, analysis and interpretation of data, and was responsible for drafting and finalizing the manuscript.

\section{ACKNOWLEDGMENT}

The authors thank Tracy Stern, RN, and Denise Dittrich, RN, from The Queen's Medical Center Neuroscience Institute for study coordination, and University of Hawaii RMATRIX for assistance with database design.

\section{STUDY FUNDING}

This study was supported in part by the National Institute on Minority Health and Health Disparities of the NIH (P20MD000173) and in part by the American Heart Association (11CRP7160019). The content is solely the responsibility of the authors and does not necessarily represent the official views of the NIH or American Heart Association.

\section{DISCLOSURE}

The authors report no disclosures relevant to the manuscript. Go to Neurology.org for full disclosures.

Received July 26, 2014. Accepted in final form October 27, 2014

\section{REFERENCES}

1. Qureshi AI, Mendelow AD, Hanley DF. Intracerebral haemorrhage. Lancet 2009;373:1632-1644.

2. Stansbury JP, Jia H, Williams LS, Vogel WB, Duncan PW. Ethnic disparities in stroke: epidemiology, acute care, and postacute outcomes. Stroke 2005;36:374-386.

3. Sacco RL, Boden-Albala B, Gan R, et al. Stroke incidence among white, black, and Hispanic residents of an urban community: the Northern Manhattan Stroke Study. Am J Epidemiol 1998;147:259-268.

4. Sacco RL, Boden-Albala B, Abel G, et al. Race-ethnic disparities in the impact of stroke risk factors: the Northern Manhattan Stroke Study. Stroke 2001;32: 1725-1731.

5. Nakagawa K, Koenig MA, Seto TB, Asai SM, Chang CW. Racial disparities among Native Hawaiians and Pacific Islanders with intracerebral hemorrhage. Neurology 2012; 79:675-680.

6. Sakai JT, Wang C, Price RK. Substance use and dependence among Native Hawaiians, other Pacific Islanders, and Asian ethnic groups in the United States: contrasting multiple-race and single-race prevalence rates from a national survey. J Ethn Subst Abuse 2010;9:173-185.

7. Winslow BT, Voorhees KI, Pehl KA. Methamphetamine abuse. Am Fam Physician 2007;76:1169-1174.
8. Edwards C, Giroux D, Okamoto SK. A review of the literature on Native Hawaiian youth and drug use: implications for research and practice. J Ethn Subst Abuse 2010;9:153-172.

9. Morgenstern LB, Hemphill JC III, Anderson C, et al. Guidelines for the management of spontaneous intracerebral hemorrhage: a guideline for healthcare professionals from the American Heart Association/American Stroke Association. Stroke 2010;41:2108-2129.

10. Hixson L, Hepler BB, Kim MO. The Native Hawaiian and Other Pacific Islander Population: 2010. Available at: http://www.census.gov/prod/cen2010/briefs/c2010br-12. pdf. Accessed December 6, 2012.

11. Kothari RU, Brott T, Broderick JP, et al. The ABCs of measuring intracerebral hemorrhage volumes. Stroke 1996;27:1304-1305.

12. Mau MK, Asao K, Efird J, et al. Risk factors associated with methamphetamine use and heart failure among Native Hawaiians and other Pacific Island peoples. Vasc Health Risk Manag 2009;5:45-52.

13. Won S, Hong RA, Shohet RV, Seto TB, Parikh NI. Methamphetamine-associated cardiomyopathy. Clin Cardiol 2013;36:737-742.

14. de los Rios F, Kleindorfer DO, Khoury J, et al. Trends in substance abuse preceding stroke among young adults: a population-based study. Stroke 2012;43:3179-3183.

15. Fleckenstein AE, Volz TJ, Riddle EL, Gibb JW, Hanson GR. New insights into the mechanism of action of amphetamines. Annu Rev Pharmacol Toxicol 2007;47: 681-698.

16. Hart CL, Gunderson EW, Perez A, et al. Acute physiological and behavioral effects of intranasal methamphetamine in humans. Neuropsychopharmacology 2008;33: 1847-1855.

17. Berankova K, Habrdova V, Balikova M, Strejc P. Methamphetamine in hair and interpretation of forensic findings in a fatal case. Forensic Sci Int 2005;153:93-97.

18. Delaney P, Estes M. Intracranial hemorrhage with amphetamine abuse. Neurology 1980;30:1125-1128.

19. Shibata S, Mori K, Sekine I, Suyama H. Subarachnoid and intracerebral hemorrhage associated with necrotizing angiitis due to methamphetamine abuse: an autopsy case. Neurol Med Chir 1991;31:49-52.

20. Moriya F, Hashimoto Y. A case of fatal hemorrhage in the cerebral ventricles following intravenous use of methamphetamine. Forensic Sci Int 2002;129:104-109.

21. Perez JA Jr, Arsura EL, Strategos S. Methamphetaminerelated stroke: four cases. J Emerg Med 1999;17:469-471.

22. Ho EL, Josephson SA, Lee HS, Smith WS. Cerebrovascular complications of methamphetamine abuse. Neurocrit Care 2009; 10:295-305.

23. Harrington $\mathrm{H}$, Heller HA, Dawson D, Caplan L, Rumbaugh C. Intracerebral hemorrhage and oral amphetamine. Arch Neurol 1983;40:503-507.

24. Weiss SR, Raskind R, Morganstern NL, Pytlyk PJ, Baiz TC. Intracerebral and subarachnoid hemorrhage following use of methamphetamine ("speed”). Int Surg 1970; 53:123-127.

25. Olsen ER. Intracranial hemorrhage and amphetamine usage: review of the effects of amphetamines on the central nervous system. Angiology 1977;28:464-471.

26. Cahill DW, Knipp H, Mosser J. Intracranial hemorrhage with amphetamine abuse. Neurology 1981;31:10581059 . 
27. Miyashita T, Hayashi T, Ishida $\mathrm{Y}$, Tsuneyama K, Kimura A, Kondo T. A fatal case of pontine hemorrhage related to methamphetamine abuse. J Forensic Leg Med 2007;14:444-447.

28. Citron BP, Halpern M, McCarron M, et al. Necrotizing angiitis associated with drug abuse. N Engl J Med 1970; 283:1003-1011.

29. Kessler JT, Jortner BS, Adapon BD. Cerebral vasculitis in a drug abuser. J Clin Psychiatry 1978;39:559-564.

30. Halpern M, Citron BP. Necrotizing angiitis associated with drug abuse. Am J Roentgenol Radium Ther Nucl Med 1971;111:663-671.

31. Rumbaugh CL, Bergeron RT, Fang HC, McCormick R. Cerebral angiographic changes in the drug abuse patient. Radiology 1971;101:335-344.

32. Yu YJ, Cooper DR, Wellenstein DE, Block B. Cerebral angiitis and intracerebral hemorrhage associated with methamphetamine abuse: case report. J Neurosurg 1983; 58:109-111.

33. Aggarwal SK, Williams V, Levine SR, Cassin BJ, Garcia JH. Cocaine-associated intracranial hemorrhage: absence of vasculitis in 14 cases. Neurology 1996;46: 1741-1743.

34. McGee SM, McGee DN, McGee MB. Spontaneous intracerebral hemorrhage related to methamphetamine abuse: autopsy findings and clinical correlation. Am J Forensic Med Pathol 2004;25:334-337.

35. Karch SB, Stephens BG, Ho CH. Methamphetaminerelated deaths in San Francisco: demographic, pathologic, and toxicologic profiles. J Forensic Sci 1999;44: 359-368.

36. Kaye S, McKetin R, Duflou J, Darke S. Methamphetamine and cardiovascular pathology: a review of the evidence. Addiction 2007;102:1204-1211.

\section{Learn How to Become a Leader in Changing Health Care}

Do you have ideas on how to improve health care? Learn to become an advocacy leader in your clinic, institution, or community. Apply for the 2015 Palatucci Advocacy Leadership Forum. This distinctive advocacy training program will be held January 15-18, 2015, at the Omni Amelia Island Plantation Resort near Jacksonville, FL. Applications are due by September 21, 2014.

Graduates of the Palatucci Forum are successfully creating positive and lasting changes for their patients and their profession across the globe. Many of today's Academy leaders have participated in this advocacy training and recommend it. For more information or to apply, visit $A A N$.com/view/ 2015palf or contact Melissa Showers at mshowers@aan.com or (612) 928-6056.

\section{Enjoy Big Savings on NEW 2015 AAN Practice Management Webinar Subscriptions}

The American Academy of Neurology offers 14 cost-effective Practice Management Webinars which you can attend live or listen to recordings posted online. AAN members can purchase one webinar for $\$ 149$ or subscribe to the entire series for only $\$ 199$ - a big savings from the 2015 nonmember price of $\$ 199$ per webinar or $\$ 649$ for the subscription. Register today for upcoming webinars, access recorded webinars, and see the rest of the 2015 schedule at $A A N$.com/ view/pmw15:

- January 20: Now is the Time: Getting Paid for Chronic Care Coordination

- February 10: Coding for Neurodiagnostic Procedures Made Easy

- March 3: Case Studies: Neurologists Succeeding in New Health Care Models

- March 24: Improving Your Referral Network 